\title{
TỶ LÊ ĐẠT MỤC TIÊU KIỂM SOÁT ĐƯờNG HUYẾT TRÊN BỆNH NHÂN ĐÁI THÁO ĐƯờnG TÍP 2 TẠI PHÒNG KHÁM NỘI TIẾT BỆNH VIỆN ĐA KHOA HOÀN MỸ CỦU LONG
}

\author{
Thạch Thị Phola \\ Bệnh viện Đa khoa Hoàn Mỹ Cưu Long
}

DOI: $10.47122 / v j d e .2020 .45 .4$

\section{TÓM TẮT}

Đặt vấn đề: Để ngăn ngừa và làm giảm các biến chứng của bệnh đái tháo đường, việc kiểm soát đường huyết theo mục tiêu cho bệnh nhân là điều bắt buộc. Tại Việt Nam, có một số nghiên cứu khảo sát tỷ lệ đạt mục tiêu $\mathrm{HbA1c}$ trên bệnh nhân đái tháo đường típ 2, nhìn chung tỷ lệ đạt còn thấp, dao động khoảng 30 - 40\%. Tuy nhiên vẫn chưa có nghiên cứu cụ thể về tỷ lệ này tại Phòng khám Nội tiết, Bệnh viện Hoàn Mỹ Cửu Long. Mục tiêu: $\quad$ 1) Khảo sát đặc điểm lâm sàng và cận lâm sàng; 2) Xác định tỷ lệ đạt mục tiêu điều trị và một số yếu tố liên quan sau 06 tháng ở bệnh nhân đái tháo đường típ 2 điều trị tại phòng khám Nội tiết, bệnh viện Hoàn Mỹ Cửu Long. Đối tự̛ng và phuơng pháp nghiên cứu: Nghiên cứu tiến cứu, mô tả cắt ngang, được tiến hành trên 514 bệnh nhân đái tháo đường típ 2 đang điều trị tại Phòng khám Nội tiết, Bệnh viện Hoàn Mỹ Cửu Long từ tháng 03 năm 2019 đến tháng 12 năm 2019. Kết quả: Có $64 \%$ đối tượng là nữ, độ tuổi $<65$ chiếm $71 \%$, tuổi trung bình $59 \pm 11,88$, nhỏ nhất 17 và lớn nhất 93 tuổi; $41,4 \%$ có thời gian mắc bệnh $<5$ năm, thời gian trung bình mắc bệnh $6,92 \pm 5,06$. Thể trạng bình thường: $43,8 \%$, thừa cân $28,2 \%$. Có $50 \%$ đối tượng mắc bệnh THA, 45,5\% bệnh mạch vành, $77,6 \%$ rối loạn lipid máu. Tuân thủ chế độ ăn tốt $28,6 \%$, kém $30,9 \%$. Tuân thủ vận động thể lực $<3$ lần/tuần đạt $39,5 \%$, không vận động $42 \%$. Điều trị phối hợp 02 nhóm thuốc viên $31,1 \%$, dùng phối hợp insulin và thuốc viên $28 \%$. Kết quả đường huyết đói và $\mathrm{HbA} 1 \mathrm{c}$ đạt mục tiêu sau 6 tháng lần lượt là $54,9 \%$ và $44,9 \%$. Nhóm tuổi $<65$ tuổi có hiệu quả kiểm soát $\mathrm{HbA} 1 \mathrm{c} \leq 7 \%$ cao gấp 1,82 lần so nhóm $\geq$ 65 tuổi. Nhóm đối tượng tuân thủ chế độ ăn tốt kiểm soát $\mathrm{HbA} 1 \mathrm{c} \leq 7 \%$ so với các nhóm còn lại lần lượt: 5,04 lần và 9,39 lần. Nhóm đối tượng trước can thiệp có $\mathrm{HbA} 1 \mathrm{c} \leq 7 \%$ duy trì tỷ lệ HbA1c cao gấp 5,27 lần. Kết luận: HbA1c đạt mục tiêu sau 6 tháng điều trị chiếm tỷ lệ cao. Bệnh nhân nhỏ tuổi, tuân thủ chế độ ăn tốt và mức $\mathrm{HbA} 1 \mathrm{c}$ ban đầu là các yếu tố liên quan độc lập đến kiểm soát $\mathrm{HbA} 1 \mathrm{c} \leq 7 \%$ sau 6 tháng điều trị.

Tù khóa: Đái tháo đường típ 2, đường huyết, $H b A l c$.

\section{ABSTRACT \\ The rate of achievement glycemic control target on type 2 diabetes patients at endocrine disease clinic of Hoan My Cuи Long General Hospital \\ Thach Thi Phola \\ Hoan My Cuu Long General Hospital}

Background: To prevent and reduce the complications of diabetes, targeted blood glucose control for the patient is imperative. In Vietnam, a number of studies have investigated the rate of achieving $\mathrm{HbAlc}$ targets in type 2 diabetes patients, in general, the rate is low, ranging from $30-40 \%$. However, there are no specific studies on this ratio at the Endocrinology Clinic, Hoan My Cuu Long General Hospital. Objectives: 1) Survey clinical and subclinical characteristics; 2) Determine the rate of achieving treatment goals and some factors related to treatment results after 6 months in type 2 diabetes patients treated in the Endocrinology clinic. Hoan My Cuu Long General Hospital. Subjects and methods: Progressive, crosssectional description Study, conducted on 514 type 2 diabetes patients who are being treated at the Endocrinology Clinic, Hoan My Cuu Long General Hospital from March 2019 to December 2019. Results: $64 \%$ of subjects are 
female, accounting for $71 \%$ of the age $<65$, the mean age $59 \pm 11.88$, the minimum age of 17 and the oldest 93 years old; $41.4 \%$ had duration of disease $<5$ years, mean time was $6.92 \pm 5.06$. Normal condition: $43.8 \%$, overweight $28.2 \%$. There are $50 \%$ of subjects with hypertension, $45.5 \%$ coronary artery, $77.6 \%$ dyslipidemia. Adhering to a good diet $28.6 \%$, poor $30.9 \%$. Keeping to exercise $<3$ times/week reached $39.5 \%$, not keeping is $42 \%$. Treatment with 2 oral antidiabetes drugs is $31.1 \%$, using a combination of insulin and $\mathrm{OAD}$ is $28 \%$. The results of fasting blood sugar and $\mathrm{HbAlc}$ reaching the target after 6 months are $54.9 \%$ and $44.9 \%$ respectively. The control effect of $\mathrm{HbA} 1 \mathrm{C} \leq 7 \%$ in the group $<65$ years old is 1.82 times higher than that in the $\geq$ 65 year old group; The subjects who adhering to a good diet has better controlled $\mathrm{HbAlc} \leq$ 7\% than other groups: 5.04 times and 9.39 times, respectively. The pre-intervention group who have HbAlc $\leq 7 \%$ have maintained HbAlc rate 5.27 times higher other group. Conclusion: $\mathrm{HbAlc}$ achieved the target after 6 months of treatment with a high rate. Young patients, good dietary adherence and baseline HbAlc levels were independent factors in controlling $\mathrm{HbAlc} \leq 7 \%$ after 6 months of treatment.

Keywords: Type 2 diabetes, blood glucose, HbAlc.

Chịu trách nhiệm chính: Thạch Thị Phola

Ngày nhận bài: 15/12/2020

Ngày phản biện khoa học: 11/1/2021

Ngày duyệt bài: 25/02/2021

Email: ttphola@gmail.com

Điện thoại: 0904580845

\section{1. ĐẶT VẤN ĐỀ}

Theo thống kê của Liên đoàn đái tháo đường thế giới, năm 2015 thế giới có 415 triệu người mắc bệnh đái tháo đường, trong đó $56 \%$ người bệnh đái tháo đường đang sống ở khu vực Đông Nam Á hoặc vùng Tây Thái Bình Dương [12]. Tại Việt Nam, tỷ lệ mắc bệnh đái tháo đường là $5,5 \%$, và khu vực Đồng bằng sông Cửu Long có tỷ lệ mắc bệnh cao nhất $7,2 \%$ [1]. Để ngăn ngừa hay làm giảm các biến chứng của bệnh đái tháo đường, việc điều trị nhằm kiểm soát đường huyết theo mục tiêu hiện nay là điều bắt buộc. Mặc dù luôn nổ lực để điều trị tích cực, nhưng nhiều bệnh nhân đái tháo đường típ 2 vẫn không đạt được mục tiêu đường huyết. Ở Mỹ theo điều tra về sức khỏe và dinh dưỡng năm 2003 - 2004, tỷ lệ đạt mục tiêu HbAlc 1à 56,8\% [11]. Ở 8 nước Châu Á 2005 là 37,3\% [8], Tại Việt Nam theo Diabcare-Asia 1998 là 18\% [9], theo chương trình JADE là $29 \%$ [13]. Biết được thực trạng kiểm soát đường huyết của bệnh nhân đái tháo đường típ 2 và các yếu tố liên quan tại một địa phương, bệnh viện là rất cần thiết vì vậy, chúng tôi tiến hành nghiên cứu đề tài với 02 mục tiêu:

1. Khảo sát đặc điểm lâm sàng, cận lâm sàng ơ bệnh nhân đái tháo đường típ 2;

2. Xác định tỷ lệ đạt mục tiêu điều trị và các yếu tố liên quan sau 06 tháng ở bệnh nhân đái tháo đương típ 2 điều trị tại phòng khám nội tiết Bệnh viện Hoàn Mỹ Củu Long năm 2019.

\section{2. ĐỐI TƯợNG VÀ PHƯƠNG PHÁP NGHIÊN CÚ'U}

2.1. Đối tượng nghiên cứu: Tất cả bệnh nhân đái tháo đường típ 2 điều trị ngoại trú tại khoa khám bệnh, Bệnh viện Hoàn Mỹ Cửu Long từ tháng $3 / 2019$ đến tháng 12/2019.

Tiêu chuẩn chọn: Bệnh nhân đái tháo đường típ 2 được chẩn đoán theo tiêu chí của ADA 2018, còn tỉnh táo để trả lời phỏng vấn, đồng ý tham gia nghiên cứu.

Tiêu chuẩn loại: Bệnh nhân đái tháo đường mới phát hiện hoặc đang được điều trị tại phòng khám nhưng dưới 03 tháng; đái tháo đường thai kỳ; đái tháo đường típ 1 ; có bệnh thận mạn giai đoạn 4 trở lên; xơ gan child B,C; bệnh lý huyết học.

\subsection{Phương pháp nghiên cứu}

Thiết kế nghiên cứu: Nghiên cứu tiến cứu, mô tả cắt ngang.

Cõ mẫu: 514 bệnh nhân thỏa tiêu chuẩn chọn mẫu được chọn vào nghiên cứu trong thời gian từ tháng 3 năm 2019 đến tháng 12 năm 2019.

Nội dung nghiên cứu:

- Đặc điểm chung của đối tượng nghiên cứu: Tuổi, giới, nghề nghiệp. 
- Đặc điểm lâm sàng: Thời gian mắc bệnh ĐTĐ, tiền sử bệnh tật, BMI, tuân thủ chế độ ăn, vận động thể lực, thuốc đang điều trị: thuốc viên, thuốc viên và insulin, insulin đơn thuần.

- Đặc điểm cận lâm sàng: Glucose, HbAlc, Cholesterol, Triglycerid, LDL-c, HDL-c.

- Đánh giá kết quả đường huyết đạt mục tiêu trước và sau can thiệp: Glucose, $\mathrm{HbA1c}$ sau 6 tháng.
Glucose: $\leq 7,2 \mathrm{mmol} / \mathrm{L}$ : đạt mục tiêu.

HbA1c $\leq 7 \%$ : đạt mục tiêu.

- Một số yếu tố liên quan với kiểm soát HbAlc đạt mục tiêu: Nhóm tuổi, giới, thời gian mắc bệnh ĐTĐ, tuân thủ chế độ ăn, vận động thể lực, BMI, nhóm thuốc đang điều trị, HbA1c, đường huyết đói (glucose).

Xử lý số liệu:

Số liệu được xử lý và phân tích bằng phần mềm SPSS 20.0

\section{KẾT QUẢ NGHIÊN CỨU}

\section{1. Đặc điểm chung của đối tượng nghiên cứu}

Bảng 1. Đặc điểm chung của đổi tượng nghiên cứu

\begin{tabular}{|c|c|c|c|}
\hline \multicolumn{2}{|c|}{ Đặc điểm } & $\mathbf{n}=\mathbf{5 1 4}$ & Tỷ lệ (\%) \\
\hline \multicolumn{2}{|c|}{ Tuổi TB \pm ĐLC (nhỏ nhất - lớn nhất) } & \multicolumn{2}{c|}{$59 \pm 11,88(17-93)$} \\
\hline \multirow{2}{*}{ Tuổi } & $<65$ & 363 & 70,6 \\
\cline { 2 - 4 } & $\geq 65$ & 151 & 29,4 \\
\hline \multirow{2}{*}{ Giơoi } & Nam & 184 & 36,0 \\
\cline { 2 - 4 } & Nữ & 330 & 64,0 \\
\hline
\end{tabular}

\section{Nhận xét:}

Độ tuổi mắc bệnh đái tháo đường trung bình 59 tuổi, nhỏ nhất 17 tuổi, lớn nhất 93 , nhóm tuổi $<65$ chiếm 70,6\%. 64\% là nữ giới.

\section{2. Đặc điểm lâm sàng và cận lâm sàng}

Bảng 2. Đặc điểm lâm sàng và cận lâm sàng của đối tượng nghiên cứu

\begin{tabular}{|c|c|c|c|}
\hline \multicolumn{2}{|c|}{ Đặc điểm } & Có (n) & Tỷ lệ (\%) \\
\hline \multicolumn{2}{|c|}{ Thời gian mắc bệnh $\mathrm{TB} \pm \mathrm{DLC}$} & \multicolumn{2}{|c|}{$6,92 \pm 5,055$} \\
\hline \multicolumn{2}{|c|}{$<5$ năm } & 213 & 41,4 \\
\hline \multicolumn{2}{|c|}{5 - 10 năm } & 195 & 37,9 \\
\hline \multicolumn{2}{|c|}{ > 10 năm } & 106 & 20,6 \\
\hline \multicolumn{4}{|l|}{ Tiền sử bệnh } \\
\hline \multicolumn{2}{|c|}{ Tăng huyết áp } & 257 & 50 \\
\hline \multicolumn{2}{|c|}{ Bệnh động mạch ngoại biên } & 27 & 5,3 \\
\hline \multicolumn{2}{|c|}{ Bệnh mạch vành } & 234 & 45,5 \\
\hline \multicolumn{2}{|c|}{ Bệnh mạch máu não } & 12 & 2,3 \\
\hline \multicolumn{2}{|c|}{ Bệnh võng mạc } & 2 & 0,4 \\
\hline \multicolumn{2}{|c|}{ Rối loạn lipid máu } & 399 & 77,6 \\
\hline \multicolumn{2}{|c|}{ BMI $\quad \mathrm{TB} \pm$ ĐLC } & \multicolumn{2}{|c|}{$23,5 \pm 3,0$} \\
\hline$<18,5$ & Gầy & 15 & 2,9 \\
\hline $18,5-22,9$ & Bình thường & 225 & 43,8 \\
\hline $23-24,9$ & Thừa cân & 145 & 28,2 \\
\hline $25-29,9$ & Béo phì độ I & 108 & 21,0 \\
\hline$\geq 30$ & Béo phì độ II & 21 & 4,1 \\
\hline
\end{tabular}




\begin{tabular}{|c|c|c|c|}
\hline \multicolumn{4}{|l|}{ Thuốc điều trị } \\
\hline \multirow{3}{*}{ Thuốc viên } & 1 nhóm & 97 & 18,9 \\
\hline & 2 nhóm & 160 & 31,1 \\
\hline & $\geq 3$ nhóm & 77 & 15 \\
\hline \multicolumn{2}{|c|}{ Thuốc viên + insullin } & 144 & 28 \\
\hline \multicolumn{2}{|c|}{ Insullin } & 21 & 4,1 \\
\hline \multicolumn{2}{|c|}{ Không dùng thuốc } & 19 & 3,7 \\
\hline \multicolumn{4}{|c|}{ Tuân thủ chế độ ăn } \\
\hline \multicolumn{2}{|c|}{ Tuân thủ tốt (> 5 ngày/tuần) } & 147 & 28,6 \\
\hline \multicolumn{2}{|c|}{ Trung bình (> 2 ngày/tuần) } & 208 & 40,5 \\
\hline \multicolumn{2}{|c|}{ Tuân thủ kém (<2 ngày/tuần) } & 159 & 30,9 \\
\hline \multicolumn{4}{|c|}{ Tuân thủ vận động } \\
\hline \multicolumn{2}{|c|}{ Không vận động } & 216 & 42,0 \\
\hline \multicolumn{2}{|c|}{ <3 lần/tuần } & 203 & 39,5 \\
\hline \multicolumn{2}{|c|}{$3-5$ lần/tuần } & 95 & 18,5 \\
\hline
\end{tabular}

Nhận xét:

Thời gian mắc bệnh trung bình 6,92 năm. Trong đó nhóm $<5$ năm chiếm tỷ lệ cao nhất $41,1 \%$. $50 \%$ đối tượng có tăng huyết áp, $45,5 \%$ có bệnh mạch vành, $77,6 \%$ có rối loạn lipid máu. Chỉ số BMI bình thường $43,8 \%$, đối tượng thừa cân và béo phì chiếm $53,3 \%$. Nhóm tuân thủ chế độ ăn tốt $28,6 \%$. Nhóm không vận động thể lực chiếm $42 \%$.

3.3. Đánh giá kết quả đường huyết đạt mục tiêu trước và sau can thiệp

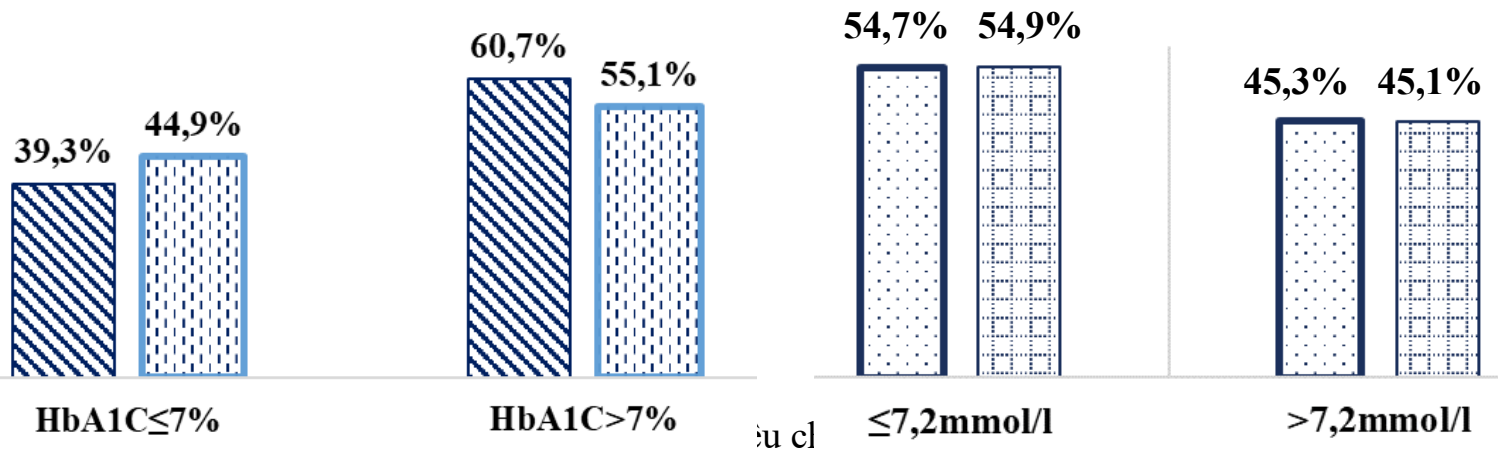

QTrước can thiệp অ Sau can thiệp

Ⓣrước can thiệp $\square$ Sau can thiệp

3.4. Một số yếu tố liên quan đến việc kiểm soát dương nuyet dạt mục tıeu

Bảng 3. Các yếu tố liên quan việc kiểm soát đường huyết đạt hiệu quả

\begin{tabular}{|c|c|c|c|c|c|}
\hline \multirow{2}{*}{\multicolumn{2}{|c|}{ Yếu tố }} & \multicolumn{2}{|c|}{ Sau can thiệp } & \multirow{2}{*}{$\begin{array}{c}\text { OR } \\
\text { Cl } 95 \%\end{array}$} & \multirow{2}{*}{$\mathbf{p}$} \\
\hline & & HbA1c $\leq 7 \%$ & HbA1c $>7 \%$ & & \\
\hline \multicolumn{6}{|c|}{ Đặc điểm chung } \\
\hline \multirow{2}{*}{ Tuổi } & $<65$ & $181(49,9 \%)$ & $182(50,1 \%)$ & \multirow{2}{*}{$\begin{array}{c}\mathbf{2 , 0 1} \\
(1,35-2,99)\end{array}$} & \multirow{2}{*}{$p<0,001$} \\
\hline & $\geq 65$ & $50(33,1 \%)$ & $101(66,9 \%)$ & & \\
\hline \multirow{2}{*}{ Giới } & Nam & $101(54,9 \%)$ & $83(45,1 \%)$ & \multirow{2}{*}{$\begin{array}{c}1.89 \\
(1,30-2,70)\end{array}$} & \multirow{2}{*}{$\mathbf{p}<0,001$} \\
\hline & Nữ & $130(39,4 \%)$ & $200(60,6 \%)$ & & \\
\hline
\end{tabular}




\begin{tabular}{|c|c|c|c|c|c|}
\hline \multicolumn{6}{|c|}{ Thò̀i gian mắc bệnh } \\
\hline \multicolumn{2}{|c|}{$<5$ năm } & $120(56,1 \%)$ & $94(43,9 \%)$ & - & 1 \\
\hline \multicolumn{2}{|c|}{5 - 10 năm } & $81(41,5 \%)$ & $114(58,5 \%)$ & $\begin{array}{c}\mathbf{1 , 7 8} \\
(1,20-2,64)\end{array}$ & $\mathrm{p}=0,004$ \\
\hline \multicolumn{2}{|c|}{ >10 năm } & $30(28,6 \%)$ & $75(71,4 \%)$ & $\begin{array}{c}\mathbf{3 , 0 6} \\
(1,86-5,04)\end{array}$ & $\mathbf{p}<0,001$ \\
\hline \multicolumn{6}{|l|}{ BMI } \\
\hline \multicolumn{2}{|l|}{ Bình thường } & $105(46,7 \%)$ & $120(53,3 \%)$ & \multirow{2}{*}{$\begin{array}{c}1,16 \\
(0,81-1,65)\end{array}$} & \multirow{2}{*}{$\mathrm{p}=0,421$} \\
\hline Thừa cân/Be & phì & $118(43,1 \%)$ & $156(56,9 \%)$ & & \\
\hline \multicolumn{6}{|c|}{ Thuốc điều trị } \\
\hline \multirow{3}{*}{ Thuốc viên } & 1 nhóm & $61(62,9 \%)$ & $36(37,1 \%)$ & 1 & - \\
\hline & 2 nhóm & $84(52,5 \%)$ & $76(47,5 \%)$ & $\begin{array}{c}1,53 \\
(0,92-2,57)\end{array}$ & $\mathrm{p}=0,104$ \\
\hline & $\geq 3$ nhóm & $32(41,6 \%)$ & $45(58,4 \%)$ & $\begin{array}{c}\mathbf{2 , 3 8} \\
(1,29-4,40) \\
\end{array}$ & $p=0,005$ \\
\hline \multicolumn{2}{|c|}{ Thuốc viên + insullin } & $35(24,3 \%)$ & $109(75,7 \%)$ & $\begin{array}{c}\mathbf{3 , 5 1} \\
(2,28-5,40)\end{array}$ & $\mathbf{p}<0,001$ \\
\hline \multicolumn{2}{|l|}{ Insullin } & $7(33,3 \%)$ & $14(66,7 \%)$ & $\begin{array}{c}1,67 \\
(0,66-4,2) \\
\end{array}$ & $\mathrm{p}=0,275$ \\
\hline \multicolumn{6}{|c|}{ Tuân thủ chế độ ăn } \\
\hline \multicolumn{2}{|c|}{$\begin{array}{c}\text { Tuân thủ tốt } \\
\text { (>5 ngày/tuần) }\end{array}$} & $105(71,4 \%)$ & $42(28,6 \%)$ & 1 & - \\
\hline \multicolumn{2}{|c|}{$\begin{array}{l}\text { Trung bình } \\
\text { (>2 ngày/tuần) }\end{array}$} & $76(36,5 \%)$ & $132(63,5 \%)$ & $\begin{array}{c}\mathbf{4 , 3 4} \\
(2,75-6,85)\end{array}$ & $p<0,001$ \\
\hline \multicolumn{2}{|c|}{$\begin{array}{l}\text { Tuân thủ kém } \\
\text { (<2 ngày/tuần) }\end{array}$} & $50(31,4 \%)$ & $109(68,6 \%)$ & $\begin{array}{c}\mathbf{5 , 5} \\
(3,34-8,90) \\
\end{array}$ & $\mathbf{p}<0,001$ \\
\hline \multicolumn{6}{|c|}{ Tuân thủ vận động } \\
\hline \multicolumn{2}{|c|}{$3-5$ lần/tuần } & $59(62,1 \%)$ & $36(37,9 \%)$ & 1 & - \\
\hline \multicolumn{2}{|c|}{ <3 lần/tuần } & $96(47,3 \%)$ & $107(52,7 \%)$ & $\begin{array}{c}\mathbf{1 , 8 3} \\
(1,11-3,01)\end{array}$ & $p=0,018$ \\
\hline \multicolumn{2}{|c|}{ Không vận động } & $76(35,2 \%)$ & $140(64,8 \%)$ & $\begin{array}{c}\mathbf{3 . 0 2} \\
(1,83-5,00) \\
\end{array}$ & $\mathbf{p}<0,001$ \\
\hline \multicolumn{6}{|c|}{ Trước can thiệp } \\
\hline \multicolumn{2}{|c|}{$\mathrm{HbA} 1 \mathrm{c} \leq 7 \%$} & $143(70,8 \%)$ & $59(29,2 \%)$ & \multirow{2}{*}{$\begin{array}{c}\mathbf{6 , 1 7} \\
(4,17-9,12) \\
\end{array}$} & \multirow{2}{*}{$\mathbf{p}<0,001$} \\
\hline $\mathrm{HbA}$ & $>7 \%$ & $88(28,2 \%)$ & $224(71,8 \%)$ & & \\
\hline \multicolumn{6}{|c|}{ Đường huyết lúc đói trước can thiệp } \\
\hline \multicolumn{2}{|c|}{$\leq 7,2 \mathrm{mmol} / 1$} & $156(55,5 \%)$ & $125(44,5 \%)$ & \multirow{2}{*}{$\begin{array}{c}\mathbf{2 , 6 3} \\
(1,83-3,78)\end{array}$} & \multirow{2}{*}{$\mathbf{p}<\mathbf{0 , 0 0 1}$} \\
\hline$>7,2$ & $\mathrm{~mol} / 1$ & $75(32,3 \%)$ & $158(67,8 \%)$ & & \\
\hline
\end{tabular}

\section{Nhận xét:}

Một số yếu tố liên quan đến kiểm soát đường huyết đạt mục tiêu và sự khác biệt này có ý nghĩa thống kê bao gồm: nhóm tuổi, giới tính, thời gian mắc bệnh, thuốc điều trị nhóm thuốc viên hoặc phối hợp insulin và thuốc viên, tuân thủ chế độ ăn và vận động, nhóm đối tượng có chỉ số đường huyết lúc đói và $\mathrm{HbA} 1 \mathrm{c}$ trước can thiệp. 
Bảng 4. Hồi quy logictis một số đặc điểm liên quan kiểm soát đường huyết

\begin{tabular}{|c|c|c|c|}
\hline \multicolumn{2}{|c|}{ Đặc điểm } & OR (Cl 95\%) & $\mathbf{p}$ \\
\hline \multirow{2}{*}{ Nhóm tuổi } & $<65$ tuổi & \multirow{2}{*}{$\mathbf{1 , 8 2}(1,04-3,19)$} & \multirow{2}{*}{$\mathbf{0 , 0 3 6}$} \\
\hline & $\geq 65$ tuổi & & \\
\hline \multicolumn{4}{|c|}{ Tuân thủ chế độ ăn } \\
\hline \multicolumn{2}{|c|}{ Tuân thủ tốt (>5 ngày/tuần) } & - & - \\
\hline \multicolumn{2}{|c|}{ Trung bình (>2 ngày/tuần) } & $\mathbf{5 , 0 4}(2,88-8,84)$ & $\mathrm{p}<\mathbf{0 , 0 0 1}$ \\
\hline \multicolumn{2}{|c|}{ Tuân thủ kém (<2 ngày/tuần) } & $\mathbf{9 , 3 9}(4,98-17,72)$ & $\mathrm{p}<0,001$ \\
\hline \multicolumn{4}{|c|}{ Trước can thiệp } \\
\hline \multicolumn{2}{|c|}{$\mathrm{HbA} 1 \mathrm{c} \leq 7 \%$} & \multirow{2}{*}{$\mathbf{5 , 2 7}(3,25-8,60)$} & \multirow{2}{*}{$\mathbf{p}<\mathbf{0 , 0 0 1}$} \\
\hline \multicolumn{2}{|c|}{$\mathrm{HbA} 1 \mathrm{c}>7 \%$} & & \\
\hline
\end{tabular}

\section{Nhận xét:}

Kết quả phân tích đa biến cho thấy: có 3 biến độc lập thật sự có ý nghĩa thống kê dự đoán cho việc kiểm soát đường huyết đạt mục tiêu. Nhóm tuổi $<65$ tuổi kiểm soát $\mathrm{HbAlc}$ đạt mục tiêu cao gấp 1,82 lần so với nhóm có độ tuổi $\geq 65$ tuổi. Nhóm đối tượng tuân thủ chế độ ăn tốt có tỷ lệ kiểm soát HbA1c đạt hiệu quả cao gấp 5,04 lần so nhóm tuân thủ trung bình, cao gấp 9,39 lần so nhóm tuân thủ chế độ ăn kém. Nhóm đối tượng trước can thiệp có $\mathrm{HbA} 1 \mathrm{c} \leq 7 \%$ có tỷ lệ duy trì tỷ lệ kiểm soát HbA1c đạt hiệu quả cao gấp 5,27 lần so với nhóm đối tượng ban đầu có $\mathrm{HbA} 1 \mathrm{c}>7 \%$.

\section{BÀN LUẬn}

\section{1. Đăc điểm lâm sàng và cận lâm sàng}

Thời gian mắc bệnh trung bình là $6,92 \pm$ 5,05 năm, trong đó phát hiện đái tháo đường típ 2 sớm nhất là 1 năm và thời gian mắc bệnh dài nhất là 21 năm. Tác giả Bùi Thị Khánh Thuận ghi nhận thời gian mắc bệnh trung bình là 7,3 土 6.5 năm [7]; Nguyễn Khánh Ly nghiên cứu trên đối tượng bệnh nhân ngoại trú khám ở tuyến quận huyện cũng ghi nhận thời gian mắc bệnh trung bình 7,8 $\pm 5,2$ năm [4].

Trong nghiên cứu của chúng tôi có $28,6 \%$ bệnh nhân tuân thủ tốt chế độ ăn và $28,6 \%$ vận động thể lực $>5$ lần/tuần. Tỷ lệ bệnh nhân tuân thủ tốt chế độ ăn uống và vận động trong nghiên cứu chúng tôi thấp hơn so với nghiên cứu của tác giả Hứa Thành Nhân: tuân thủ tốt chế độ ăn là 46,7\% và tuân thủ tốt chế độ vận động là 46,2\% [6].

Chỉ số khối cơ thể (BMI) trong nghiên cứu chúng tôi trung bình là $23,5 \pm 3 \mathrm{~kg} / \mathrm{m}^{2}$, tỷ lệ thừa cân là $28,2 \%$, béo phì độ $\mathrm{I}$ là $21 \%$, béo phì độ II 4,1\%. Theo nghiên cứu của Nguyễn Thị Thanh Nga năm 2003 ghi nhận BMI trung bình là $23,7 \mathrm{~kg} / \mathrm{m} 2$, tỷ lệ béo phì là $31,5 \%$ [5]. Đến năm 2014 , tỷ lệ béo phì trong nghiên cứu của tác giả Hứa Thành Nhân là $45 \%$ và $\mathrm{BMI}$ trung bình là $24,9 \pm 3,5 \mathrm{~kg} / \mathrm{m} 2$ [6].

Đa số bệnh nhân trong nghiên cứu của chúng tôi có tiền căn tăng huyết áp, chiếm tỷ lệ $50 \%$ và rối loạn lipid máu là $77,6 \%$. Theo nghiên cứu của tác giả Hứa Thành Nhân tỷ lệ tăng huyết áp cũng khá cao 65,8\% [6]. Theo thời gian, tỷ lệ tăng huyết áp tăng dần, năm 2005 là 52,2\% [3], năm 2007 là 58,2\% [2], năm 2014 là $83,3 \%$ [4].

\subsection{Tỷ lệ đạt mục tiêu kiểm soát đường} huyết và một số yếu tố liên quan.

Nghiên cứu của chúng tôi ghi nhận tỷ lệ đạt mục tiêu HbA1c là 44,9\%. Tại Việt Nam, theo tạp chí đái tháo đường Châu Á năm 1998 ghi nhận tỷ lệ bệnh nhân ĐTĐ đạt mục tiêu HbA1c là $18 \%$ [10]. Nghiên cứu của Yeung và cộng sự được thực hiện tại Việt Nam với sự tham gia của 705 bệnh nhân ghi nhận tỷ lệ đạt $\mathrm{HbA1c}$ là $29 \%$ [13].

Tại thành phố Hồ Chí Minh, nghiên cứu của Nguyễn Thị Thanh Nga năm 2003 tại Bệnh viện Nguyễn Trãi cho thấy tỷ lệ bệnh nhân đái 
tháo đường típ 2 đạt mục tiêu $\mathrm{HbA} 1 \mathrm{c}$ là $11,11 \%$ [5]. Gần đây nhất là nghiên cứu của Hứa Thành Nhân tại phòng khám chuyên khoa Nội tiết, Trung tâm medic thành phố Hồ Chí Minh ghi nhận tỷ lệ bệnh nhân đạt mục tiêu $\mathrm{HbA} 1 \mathrm{c}$ là 33,8\% [6].

Một số yếu tố liên quan đến kiểm soát HbAlc đạt mục tiêu và sự khác biệt có ý nghĩa thống kê bao gồm: nhóm tuổi, giới tính, thời gian mắc bệnh, thuốc điều trị nhóm thuốc viên hoặc phối hợp insulin và thuốc viên. Tuân thủ chế độ ăn và vận động, nhóm đối tượng có chỉ số đường huyết lúc đói và HbA1c trước can thiệp. Sự khác biệt không có ý nghĩa thống kê trong việc kiểm soát HbAlc đạt mục tiêu: nhóm đối tượng điều trị 2 nhóm thuốc viên và 01 nhóm thuốc viên. Nhóm có $\mathrm{BMI}$ bình thường và nhóm thừa cân, béo phì. Giữa nhóm điều trị insullin và nhóm không sử dụng insulin.

Khi phân tích hồi quy đa biến: 03 yếu tố độc lập liên quan đến kiểm soát $\mathrm{HbA} 1 \mathrm{c}$ đạt hiệu quả: Nhóm tuổi, tuân thủ chế độ ăn và $\mathrm{HbA} 1 \mathrm{c}$ trước can thiệp.

\section{KẾT LUẬN}

Đường huyết đói và $\mathrm{HbA} 1 \mathrm{c}$ đạt mục tiêu lần lượt là $54,9 \%$ và $44,9 \%$.

Có 3 yếu tố độc lập có ý nghĩa thống kê dự đoán cho việc kiểm soát đường huyết đạt mục tiêu. Nhóm tuổi < 65 tuổi kiểm soát $\mathrm{HbA} 1 \mathrm{c}$ đạt mục tiêu cao gấp 1,82 lần so với nhóm có độ tuổi $\geq 65$ tuổi.

Nhóm đối tượng tuân thủ chế độ ăn tốt có tỷ lệ kiểm soát $\mathrm{HbA1c}$ đạt mục tiêu cao gấp 5,04 lần so nhóm tuân thủ trung bình, cao gấp 9,39 lần so nhớm đối tượng tuân thủ chế độ ạn kém. Nhóm đối tượng trước can thiệp có $\mathrm{HbA} 1 \mathrm{c} \leq 7 \%$ có tỷ lệ duy trì tỷ lệ kiểm soát HbA1c đạt mục tiêu cao gấp 5,27 lần so với nhóm đối tượng ban đầu có $\mathrm{HbA} 1 \mathrm{c}>7 \%$.

\section{TÀI LIÊU THAM KHẢO}

1. Bệnh viện Nội Tiết Trung ương (2013), Báo cáo Hội nghị tổng kết hoạt động năm 2012 và phuơng huoóng hoạt động năm 2013 của dụ án phòng chống đái tháo đường quốc gia và hoạt động phòng chống các rối loạn thiếu iod, Hà Nội.

2. Lai Quang Giao (2007), Khảo sát đặc điểm bệnh đái tháo đường type 2 trong cán bộ chiến sĩ công an nhân dân điều trị tại bệnh viện 30-4, Luận văn tốt nghiệp chuyên khoa II, Đại học Y Dược TP.HCM.

3. Nguyễn Thy Khuê (2005), "Nghiên cứu microdiabet-nghiên cứu cắt ngang dịch tể học đa trung tâm tại TP.HCM", Kỷ yếu toàn văn các nghiên cúu khoa họ - Hội nghi nội tiết và đái tháo đường toàn quốc lần thứ III, Tr. 820-829.

4. Nguyễn Khánh Ly (2014), "Khảo sát tỷ lệ bệnh nhân đạt mục tiêu kiểm soát đa yêu tố nguy cơ tim mạch ở bệnh nhân đái tháo đường típ 2 điều trị ngoại trú tại phòng khám quận, huyện", Tạp chí Y học thành phố Hồ Chí Minh, Tr. 44-52.

5. Nguyễn Thị Thanh Nga (2003), Theo dõi điều trị đái tháo đường tại một phòng khám bảo hiểm y tế, Luận văn tốt nghiệp cao học, Đại học Y Dược TP.HCM.

6. Hứa Thành Nhân (2014), Tỷ lẹ đạt muc tiêu HbAlc và một số yếu tố liên quan trên bệnh nhân đái tháo đường típ 2 tại một phòng khám chuyên khoa nội tiết, Luận văn tốt nghiệp Nội trú, Đại học Y Dược TP.HCM.

7. Bùi Thị Khánh Thuận (2019), Kiến thức, thái độ, hành vi về chế độ ăn và tập luyện ở người bệnh đái tháo đường típ 2, Luận văn tốt nghiệp cao học, Đại học Y Dược TP.HCM.

8. Chan, J.C., Gagliardino, J. J., Baik, S. H., et al (2009), "Multifaceted determinants for achieving glycemic control: the International Diabetes Management Practice Study (IDMPS)", Diabetes Care, 32(2), pp. 227-33.

9. Chetthakul, T., Pongchaiyakul, C., Tandhanand, S. (2006), "Improvement of diabetic care at Maharat Nakhon Ratchasima Hospital (the study of Diabcare-Asia from 1997 to 2003)", J Med Assoc Thai, 89(1), pp. 56-62. 
10. Chuang, L.M., Tsai, S. T., Huang, B. Y., et al (2002), "The status of diabetes control in Asia--a cross-sectional survey of 24317 patients with diabetes mellitus in 1998", Diabet Med, 19(12), pp. 978-85.

11. Ford, E.S., Li, C., Little, R. R., Mokdad, A. H. (2008), "Trends in A1C concentrations among U.S. adults with diagnosed diabetes from 1999 to 2004", Diabetes Care, 31(1), pp. 102-4.

12. Ogurtsova, K., da Rocha Fernandes, J. D.,
Huang, Y., et al. (2017), "IDF Diabetes Atlas: Global estimates for the prevalence of diabetes for 2015 and 2040", Diabetes Res Clin Pract, 128, pp. 40-50.

13. Yeung, R.O., Zhang, Y., Luk, A., et al. (2014), "Metabolic profiles and treatment gaps in young-onset type 2 diabetes in Asia (the JADE programme): a crosssectional study of a prospective cohort", Lancet Diabetes Endocrinol, 2(12), pp. 935-43. 